\title{
JOURNAL.RU
}

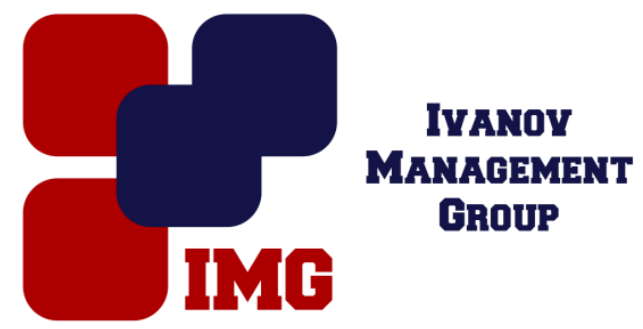

Валь Н.С., Степанова М.А. Северо-Восточный Федеральный университет имени М.К. Аммосова Якутск, Россия

doi: 10.18411/1j-30-04-2017-3-09

idsp 000001:1j-30-04-2017-3-09

\section{Управление качеством в специализированном противотуберкулезном учреждении на основе ISO 9001}

\begin{abstract}
Аннотация
В данной статье рассматривается процессный подход в управлении организацией, а именно способ его внедрения в специализированном медицинском учреждении с помощью стандарта ISO 9001 и распространение на всю деятельность организации.

Ключевые слова: процессный подход, система менеджмента качества (CMK), ISO:9001, управление медицинской организацией, менеджмент здравоохранения, медицинская организация, мониторинг и оценка результата.

Актуальность данной темы обусловлена тем, что система менеджмента качества (СМК) в здравоохранении носит универсальный, стандартизированный характер, может быть применена не только в областях, связанных с управлением качеством медицинской помощи, но во многих других областях, охватывающих многообразные аспекты деятельности учреждений сферы здравоохранения [3-5]. Цель внедрения СМК в здравоохранении состоит в достижении качества встроенного в каждый элемент деятельности организации, для удовлетворения потребностей пациентов и других заинтересованных сторон [6,8].СМК поддерживает постоянный мониторинг процессов, который помогает выявлять проблемы, планировать, внедрять и осуществлять контроль[7].

Государственное бюджетное учреждение Республики Саха (Якутия) «Научно-практический центр «Фтизиатрия» (сокращенно ГБУ РС (Я) НПЦ «Фтизиатрия») является медицинской организацией осуществляющей
\end{abstract}


специализированную, высокотехнологичную медицинскую помощь больным туберкулезом. Учредителем учреждения является Республика Саха (Якутия).

В Учреждении разработана, документирована, внедрена и поддерживается в рабочем состоянии СМК и постоянно улучшается ее результативность $[1,2]$.

Определены и детально описаны процессы, обеспечивающие предоставление медицинских услуг, а также последовательность и взаимодействие этих процессов. Все процессы представлены в виде утвержденных Карт процессов, содержащих описание этапов процесса, входные и выходные данные, нормативные документы, ресурсы, утвержденный документооборот, показатели результативности процесса.

Дополнительно к картам процессов в структурных подразделениях разработаны алгоритмы деятельности, определяющие специфику предоставления отдельных медицинских услуг (лечебных и диагностических), стандартные операционные процедуры (СОПы).

В Модели процессов и видов деятельности ГБУ $\mathrm{PC}$ (Я) НПЦ «Фтизиатрия» определены три основных процесса:

П1 «Научно-исследовательская деятельность» (КП П1 «Карта управления процессом «Научно-исследовательская деятельность»);

П2 «Оказание фтизиатрической помощи» в состав которого входят:

- П2.1 Оказание специализированной амбулаторно-поликлинической и стационарозамещающей медицинской помощи взрослым (КП П2.1 «Карта управления процессом «Оказание специализированной амбулаторно-поликлинической и стационарозамещающей медицинской помощи взрослым»);

- П2.2 Оказание специализированной амбулаторно-поликлинической медицинской помощи детям (КП П2.2 «Карта управления процессом «Оказание специализированной амбулаторно-поликлинической медицинской помощи детям»);

- П2.3 Лабораторные исследования (КП П2.3 «Карта управления процессом «Лабораторные исследования»);

- П2.4 Инструментальные исследования (КП П2.4 «Карта управления процессом «Инструментальные исследования»);

- П2.5 Оказание терапевтической помощи взрослым (КП П2.5 «Карта управления процессом «Оказание терапевтической помощи взрослым»); 
- П2.6. Оказание терапевтической помощи детям (КП П2.6 «Карта управления процессом «Оказание терапевтической помощи детям»);

- П2.7 Оказание хирургической помощи (КП П2.7 «Карта управления процессом «Оказание хирургической помощи»).

- ПЗ Инфекционный контроль (КП ПЗ «Карта управления процессом «Инфекционный контроль»).

Управляемые условия реализации лечебно-диагностического процесса включают:

- наличие порядков, клинических протоколов/рекомендаций и стандартов медицинской помощи;

- определение критериев улучшения состояния и критериев выписки пациента, наличие информации об отдаленных результатах лечения;

- наличие рабочих инструкций для медицинского персонала по критичным при оказании медицинских услуг действиям и их последовательности;

- использование соответствующего оборудования и оснащения;

- обеспечение соответствующими кадровыми ресурсами;

- внедрение мониторинга и измерений;

- наличие и использование оборудования для мониторинга и измерений;

- ведение деятельности по предоставлению медицинской услуги;

- ведение соответствующей документации, в том числе записей по качеству.

Для осуществления мониторинга, измерения и анализа процессов проведено разделение процессов по их функциональной направленности: «Управляющая деятельность» (УД), «Основные процессы» (ОП) и «Процессы обеспечения» (ПО) и отражено в «Модели процессов и видов деятельности СМК ГБУ РС (Я) «Фтизиатрия» рис.1 


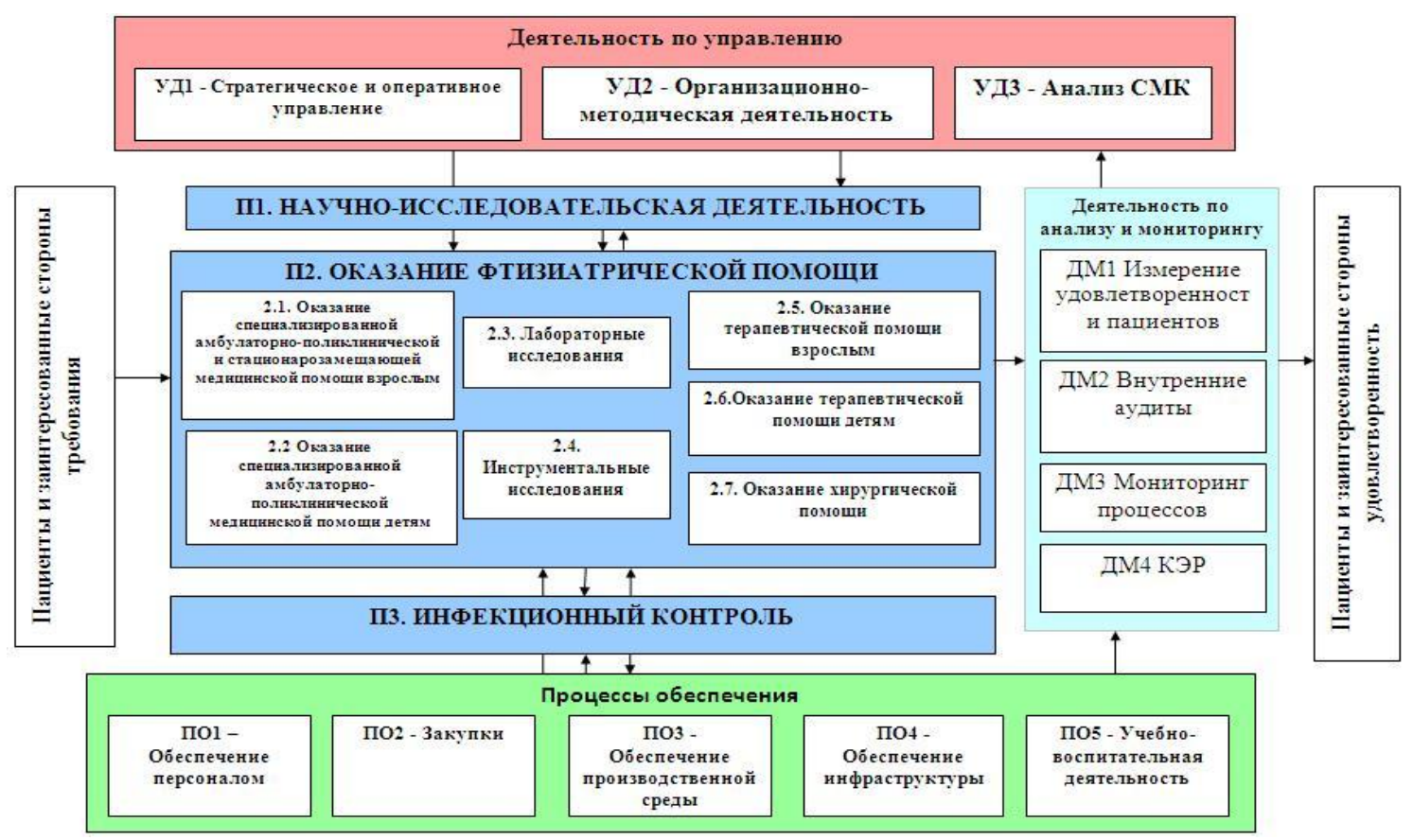

Рис.1 Модель проиессов и видов деятельности ГБУ РС (Я) НПЦ «ФТИЗИАТРИЯ»

Оценка результативности процессов деятельности ГБУ РС (Я) «НПЦ Фтизиатрия〉 производится по критериям, приведенным в картах каждого процесса. При определении методов принимается во внимание тип и объем мониторинга для измерений, соответствующий к каждому из процессов, которая определяется их влиянием на соответствие работ и услуг требованиям и на результативность СМК.

Ответственными за сбор данных, измерение и анализ результатов измерений процессов являются руководители процессов. По результатам анализа руководителями процессов устанавливается соответствие состояния процессов установленным Целям в области качества, выявляются проблемы, разрабатываются планы корректирующих и предупреждающих действий для устранения проблем и реализации постоянного улучшения.

Учреждением применяются следующие методы оценки качества медицинской помощи:

Экспертный контроль - экспертиза качества медицинской помощи проводится путём проверки соответствия предоставленной пациенту медицинской помощи по исполнению государственного заказа на оказание специализированной медицинской помощи, утверждённым порядкам оказания медицинской помощи и стандартам медицинской помощи.

Стандартизированный контроль - контроль соответствия сроков лечения и объема лечебно-диагностических процедур на основании требований стандартов медицинской помощи, определяющих технологически обоснованный объем 
медицинской помощи, состоящий из простых и сложных медицинских услуг, выполняемых больному при определенном заболевании, с определенным синдромом или при определенной клинической ситуации.

Оценка удовлетворенности пациентов качеством медицинских услуг основана на анализе информации о мнениях потребителей. Сбор информации о мнении пациентов о качестве медицинских услуг осуществляется методом анкетирования на этапе выписки пациента из стационара и при проведении внепланового анкетирования, а так же при обращении пациента в амбулаторнополиклинические подразделенияГБУ РС (Я) «НПЦ Фтизиатрия».

С целью изучения удовлетворенности потребителей проводится также анализ жалоб и рекламаций.

Результаты оценки качества медицинской помощи используются для принятия решений высшим руководством и владельцами лечебнодиагностического процесса о корректирующих и предупреждающих действиях, направленных на повышение качества предоставляемых медицинских услуг в рамках реализации политики и целей в области качества.

Таким образом, система менеджмента качества в ГБУ РС(Я) НПЦ Фтизиатрия ориентирована на удовлетворение потребностей и ожиданий всех заинтересованных сторон, опирается на применение процессного подхода и направлена на повышение результативности и эффективности работы. Учреждение обеспечивает реализацию лечебно-диагностического процесса в соответствии с запланированными и контролируемыми условиями путем проведения мероприятий по обеспечению стабильности заявленного качества и выполнения всех требований, приведенных в документации на процесс.

Установленные требования в СМК демонстрируют способность Учреждения выполнять работы и оказывать услуги, отвечающие требованиям потребителей и направленные на улучшение деятельности с учетом ожидания потребителей. 
1. ISO 9001:2015. Системы менеджмента качества. Основные положения и словарь. -3-е изд. -2014. -C. 12-15.

2. ISO 9001:2015. Системы менеджмента качества. Требования. -4-е изд. -2015. -С. 11-15.

3. Князюк Н.Ф., Кицул И.С. Методология построения интегрированной системы менеджмента медицинских организаций. - M.: Издательский дом «Менеджер здравоохранения»,2013.-312c.

4. Князюк Н.Ф. Совершенствование системы управления качеством медицинской помощи с использованием инновационных технологий: Автореф. дис. - канд. мед. наук. - Иркутск, 2006. - 29

5. Михайлова Н.В. Методология обеспечения и управления качеством медицинской помощи в соответствии с международными стандартами ИСО серии 9000.ВестникРосздравнадзора,2010,3:19-27.

6. Назаренко Г.И., Полубенцева Е.И. Управление качеством медицинской помощи. — М.: Медицина, 2000. - 368 с.

7. Нодельман В. А. Развитие теории управления комплексным качеством (TQM). В. А. Нодельман. Вестник Санкт-Петербургского университета. Серия 8. Менеджмент. СПб.: Изд-во С.-Петербургского Университета, 2004, 16(2): 69-87.

8. У Ушаков И. В., Князюк Н.Ф., Кицул И. С. Основные направления делового совершенства медицинской организации в современных условиях//Менеджер здравоохранения. 2006. №1. -C.4-13 